\title{
Differential Response of Common Bean Cultivars to Phakopsora pachyrhizi
}

\author{
M. R. Miles, United States Department of Agriculture-Agricultural Research Service (USDA-ARS), National Soy- \\ bean Research Center, University of Illinois, Urbana 61801; M. A. Pastor-Corrales, USDA-ARS, Vegetable Labora- \\ tory, Beltsville, MD 20705; G. L. Hartman, USDA-ARS, National Soybean Research Center, Department of Crop \\ Sciences, University of Illinois, Urbana; and R. D. Frederick, Foreign Disease-Weed Science Research Unit, \\ USDA-ARS, Ft. Detrick, MD 21702
}

\begin{abstract}
Miles, M. R., Pastor-Corrales, M. A., Hartman, G. L., and Frederick, R. D. 2007. Differential response of common bean cultivars to Phakopsora pachyrhizi. Plant Dis. 91:698-704.

Soybean rust (Phakopsora pachyrhizi) has been reported on common bean (Phaseolus vulgaris) in Asia, South Africa, and the United States. However, there is little information on the interaction of individual isolates of Phakopsora pachyrhizi with common bean germplasm. A set of 16 common bean cultivars with known genes for resistance to Uromyces appendiculatus, the causal agent of common bean rust, three soybean accessions that were sources of the single gene resistance to $P$. pachyrhizi, and the moderately susceptible soybean 'Ina' were evaluated using seedlings inoculated with six isolates of $P$. pachyrhizi. Among the common bean cultivars, Aurora, Compuesto Negro Chimaltenango, and Pinto 114, were the most resistant to all six P. pachyrhizi isolates, with lower severity, less sporulation, and consistent reddish-brown (RB) lesions associated with resistance in soybean. A differential response was observed among the common bean cultivars, with a cultivar-isolate interaction for both severity and sporulation levels, as well as the presence or absence of the RB lesion type. This differential response was independent of the known genes that condition resistance to $U$. appendiculatus, suggesting that resistance to $P$. pachyrhizi was independent of resistance to $U$. appendiculatus.
\end{abstract}

Soybean rust (Phakopsora pachyrhizi Syd. \& P. Syd.) has been a major disease limiting soybean production in the tropical and subtropical areas of Asia, where yield losses ranging from 10 to $80 \%$ have been reported (8). The host range of $P$. pachyrhizi is broad, with over 90 species reported in the literature, including several economically important crops. Among these are common bean (Phaseolus vulgaris L.), scarlet runner bean ( $P$. coccineus $\mathrm{L}$.), lima bean (P. lunatus L.), cowpea (Vigna unguiculata L.), pea (Pisum sativum L.), and lentil (Lens culinaris Medik.) (1,17,18, 22,28). As the pathogen spread through Africa and South America, it initially was reported on only soybean (Glycine max L.) and kudzu (Pueraria lobata (Willd.) Ohwi). However, it was identified on

Corresponding author: M. R. Miles

E-mail: mrmiles@express.cites.uiuc.edu

Trade and manufacturers' names are necessary to report factually on available data; however, the USDA neither guarantees nor warrants the standard of the product, and the use of the name by the USDA implies no approval of the product to the exclusion of others that may also be suitable.

Accepted for publication 4 January 2007.

doi:10.1094/PDIS-91-6-0698

This article is in the public domain and not copyrightable. It may be freely reprinted with customary crediting of the source. The American Phytopathological Society, 2007.
Phaseolus vulgaris, common bean, in South Africa during the 2004-05 growing season, where the pathogen was found in a germplasm evaluation trial adjacent to heavily infected soybean fields (5). The level of infection within the common bean germplasm trial was low. Few entries were infected with the pathogen, and the severity on infected leaves was much less than that observed in the adjacent soybean field.

Phakopsora pachyrhizi first was reported in the continental United States in November 2004 (23). Since the initial find in Louisiana, soybean rust has been reported on soybean or kudzu in 12 states in the southeastern United States. The first report in the United States of $P$. pachyrhizi infection on a plant species other than soybean or kudzu was on Florida beggarweed (Desmodium tortuosum (Sw.) DC.) in southwestern Georgia (24), followed by a report on Phaseolus coccineus L. (scarlet runner bean), P. lunatus L. (lima bean), and two $P$. vulgaris (kidney bean) cultivars adjacent to a rust-infected soybean field in Quincy, FL (13).

Physiological races in Phakopsora pachyrhizi were first described in Taiwan, where nine single-urediniospore isolates collected at three locations were inoculated on six soybean and five legume accessions, including common bean, Phaseolus vulgaris (12). All nine isolates produced susceptible lesions on the six soybean accessions, but were separated into six pathotypes based upon their reaction on common bean, asparagus bean, kidney bean, and short-podded yam bean. Physiological specialization had been identified in several wild legumes (4) and is well known in soybean $(2,3,7,21,25)$.

The separation of Phakopsora pachyrhizi into two species (18), P. meibomiae (Arthur) Arthur and P. pachyrhizi, has caused some confusion in interpreting previous host range studies because $P$. pachyrhizi was the species name used for all isolates $(1,22,28)$. Analysis of the nucleotide sequence of the internal transcribed spacer region of the isolates used in host range studies done at the United States Department of AgricultureAgricultural Research Service (USDAARS) Foreign Disease-Weed Science Research Unit (FDWSRU) Biosafety Level 3 (BSL-3) Plant Pathogen Containment Facility revealed that isolates from Asia were $P$. pachyrhizi, whereas isolates from Puerto Rico and Brazil were $P$. meibomiae (6). Many of the legume species evaluated in the original host range studies, including common bean, Phaseolus vulgaris, were more susceptible to Phakopsora meibomiae isolates from Brazil (BZ82-1) and Puerto Rico (PR) than the P. pachyrhizi isolate from Taiwan (TW72-1) $(22,28)$ The common bean cvs. V3249-13-1C, Ecuador 299, IAN 5091, California Small White 643, Compuesto Negro Chimaltenango (CNC), B-190, Pinto 111, Great Northern 1140, Lake Shasta, Montcalm, Rufus, and Seafarer were compared with the susceptible soybean cv. Wayne in greenhouse inoculations with $P$. meibomiae collected from Puerto Rico and Brazil, and the $P$. pachyrhizi isolate, TW72-1 (27). When inoculated with both P. meibomiae isolates, the common bean cultivars had susceptible lesions with uredinia number and size similar to those on the soybean cv. Wayne. Of the five common bean cultivars inoculated with $P$. pachyrhizi, V3249-13-1C, Ecuador 299, IAN 5091, and California Small White 643 were susceptible, producing lesions similar to those on Wayne, but CNC was highly resistant, with necrotic lesions that did not produce uredinia. Because a single $P$. pachyrhizi isolate was used in these studies, no information on physiological specialization was obtained beyond the difference between the two species. When lesion sizes and spore production were compared 
between the two Phakopsora spp. and Uromyces appendiculatus (Pers.) Unger, the causal agent of common bean rust, both soybean rust pathogens had smaller lesions with less spore production than observed with the bean rust pathogen. It was concluded that $P$. pachyrhizi was less of a threat to common bean production than U. appendiculatus (27).

Many genes for resistance to U. appendiculatus have been identified in common bean (11). Several of these genes, particularly $U r-3, U r-4, U r-5, U r-6$, and $U r-11$, have been used extensively in the USDAARS Bean Project at Beltsville, MD to develop dry and snap bean germplasm lines with resistance to $U$. appendiculatus. The first bean germplasm lines developed at Beltsville had only one or two genes for resistance. More recently, pinto and great northern bean germplasm lines have been released with four genes $(U r-3,-4,-6$, and -11) for resistance to $U$. appendiculatus $(19,20)$.

The objectives of this research were to evaluate 16 common bean cultivars with different genes for resistance to U. appendiculatus against several isolates of $P$. pachyrhizi, compare their reactions with those of the soybean accessions that were the sources of the known single gene resistance to $P$. pachyrhizi, detect any potential sources of resistance within the common bean cultivars, and determine whether there is a differential response among the resistance sources. Included in the common bean cultivars were seven bean rust differential cultivars with single resistance genes to $U$. appendiculatus; eight im- proved bean germplasm lines with two, three, and four genes for resistance to $U$. appendiculatus; and common bean cv. Pinto 114, susceptible to all current isolates of common bean rust. Although $P$. meibomiae has been shown to be a pathogen of common bean, $P$. pachyrhizi was used in this study because it is considered to be a greater threat to common bean production. $P$. pachyrhizi has spread from Asia into Africa, South America, and finally into the United States, while $P$. meibomiae has not spread from the highlands in Puerto Rico and has been found infrequently in South America.

\section{MATERIALS AND METHODS}

Sixteen selected common bean cultivars with known genes for resistance to $U$. appendiculatus (26), three soybean accessions that were sources of three of the known single genes for resistance to $P$. pachyrhizi (Rpp) $(2,9,10,14)$, and the moderately susceptible soybean 'Ina' (16) were evaluated in seedling inoculations with six isolates of $P$. pachyrhizi in the USDA-ARS FDWSRU BSL-3 Containment Greenhouse at Ft. Detrick MD (Table 1). Two seeds of each entry were planted in a single cell of a flat $(27$ by $52 \mathrm{~cm}$ ) containing $6 \times 12$ cells filled with Sunshine LC1 mix (Sun Grow Horticulture Products, Belleview, WA) and were thinned to one plant after germination. Cells on the outside edge of the flats were planted with a susceptible soybean cultivar as a border. The experimental design was a randomized complete block with three replications. Blocks were individual isolates, which

Table 1. Known resistance genes in the 16 common bean differentials and four soybean accessions inoculated with six Phakopsora pachyrhizi isolates ${ }^{\mathrm{w}}$

\begin{tabular}{|c|c|c|}
\hline Cultivar accession number or name & Type of bean & Known rust resistance genes ${ }^{x}$ \\
\hline Aurora & Common bean & $U r-3$ \\
\hline BelDakMi-RMR-14 & Common bean & $U r-3, U r-6, U r-11$ \\
\hline BelDakMi-RMR-18 & Common bean & $U r-3, U r-4, U r-6, U r-11$ \\
\hline BelDak-RR-2 & Common bean & $U r-3, U r-6, C N C$ \\
\hline BelMiDak-RMR-10 & Common bean & $U r-4, U r-11$ \\
\hline BelMiNeb-RMR-5 & Common bean & $U r-4, U r-6, U r-11$ \\
\hline BelMiNeb-RMR-7 & Common bean & $U r-4, U r-6, U r-11$ \\
\hline BelMiNeb-RMR-8 & Common bean & $U r-3, U r-4, U r-6, U r-11$ \\
\hline BelNeb-RR-1 & Common bean & $U r-5, U r-6, U r-7$ \\
\hline $\mathrm{CNC}^{\mathrm{y}}$ & Common bean & Not defined \\
\hline Early Gallatin & Common bean & $U r-4$ \\
\hline Golden White Wax & Common bean & $U r-6$ \\
\hline Mexico 309 & Common bean & $U r-5$ \\
\hline PI 181996 & Common bean & $U r-11$ \\
\hline PI 260418 & Common bean & Not defined \\
\hline Pinto 114 & Common bean & None known \\
\hline $\operatorname{Ina}^{\mathrm{z}}$ & Soybean & None known \\
\hline PI 200492 (Komata) & Soybean & Rpp1 \\
\hline PI 230970 & Soybean & Rpp 2 \\
\hline PI 459025B (Bing-Nan) & Soybean & Rpp4 \\
\hline
\end{tabular}

${ }^{w}$ A replicated seedling assay was conducted at the United States Department of Agriculture-Agricultural Research Service Foreign Disease-Weed Science Research Unit Biosafety Level 3 Plant Pathogen Containment Facility at Ft. Detrick, MD.

${ }^{x}$ Genes for resistance to Uromyces appendiculatus are noted as $\operatorname{Ur}(11,19,20)$ and genes for resistance to Phakopsora pachyrhizi are noted as Rpp $(2,9,10,14)$.

${ }^{y} \mathrm{CNC}$ is Compuesto Negro Chimaltenango; the genes for resistance for $U$. appendiculatus have not been identified but more than two are suspected.

${ }^{\mathrm{z}}$ Soybean cv. Ina is moderately susceptible to $P$. pachyrhizi; no resistance genes have been identified. were inoculated onto planting sets containing three randomized replications of the cultivars. The experiment was done four times from February 2004 through January 2006.

Six $P$. pachyrhizi isolates were used in the study. The isolates TW72-1 and TW802 were from Taiwan, collected in 1972 and 1980, respectively, and are part of the soybean rust collection at FDWSRU. The remaining four isolates were collected in 2001 from Brazil (BZ01-1), Paraguay (PG01-2), Thailand (TH01-1), and Zimbabwe (ZM01-1) (16). All P. pachyrhizi isolates were increased on the soybean cv. Williams and urediniospores were stored in liquid nitrogen. Prior to inoculation, urediniospores were removed from liquid nitrogen storage, heat shocked at $40^{\circ} \mathrm{C}$ for 5 min, and hydrated by incubating in a small plastic weigh boat over water in an enclosed petri plate overnight. Inoculum was prepared by adding urediniospores to distilled water with $0.01 \%$ Tween 20 , vigorously mixing, and then filtering the mixture through a 53- $\mu$ m nylon screen. Urediniospores were quantified using a hemacytometer and diluted in distilled water with $0.01 \%$ Tween 20 to a final concentration of 60,000 spores $/ \mathrm{ml}$ for inoculation (16).

Seedlings were inoculated when plants were 14 to 18 days old and evaluated 14 days later. Plants were atomized with 40 $\mathrm{ml}$ of the spore concentrate per flat at 20 psi until runoff, then placed in dew cham-

Table 2. Mean soybean rust severity and mean sporulation rating for each Phakopsora pachyrhizi isolate when inoculated onto 16 common bean and four soybean cultivars ${ }^{\mathrm{x}}$

\begin{tabular}{lcc}
\hline $\begin{array}{l}\text { Soybean rust } \\
\text { isolate }\end{array}$ & $\begin{array}{c}\text { Mean } \\
\text { severity }\end{array}$ & $\begin{array}{c}\text { Mean } \\
\text { sporulation }^{\mathbf{z}}\end{array}$ \\
\hline BZ01-1 & $3.1 \mathrm{~A}$ & $3.1 \mathrm{~B}$ \\
PG01-2 & $3.1 \mathrm{~A}$ & $3.1 \mathrm{~B}$ \\
TH01-1 & $2.9 \mathrm{~B}$ & $3.3 \mathrm{~A}$ \\
TW72-1 & $3.0 \mathrm{AB}$ & $2.7 \mathrm{C}$ \\
TW80-2 & $3.0 \mathrm{AB}$ & $3.1 \mathrm{~B}$ \\
ZM01-1 & $3.1 \mathrm{~A}$ & $3.3 \mathrm{~A}$ \\
\hline
\end{tabular}

${ }^{x}$ The experiment was performed four times at the United States Department of AgricultureAgricultural Research Service Foreign Disease-Weed Science Research Unit Biosafety Level 3 Plant Pathogen Containment Facility in Ft. Detrick, MD. Means with different letters were significantly different using Student's least significant difference $(P=0.05)$.

y Soybean rust severity was evaluated on a 1-to5 scale based on lesion density, where $1=$ no visible lesions, $2=$ few scattered lesions present, $3=$ moderate number of lesions, $4=$ abundant number of lesions, and $5=$ prolific lesion development over most of the leaf.

${ }^{\mathrm{z}}$ Sporulation within lesions was evaluated on a 1-to-5 scale, where $1=$ no sporulation, $2=$ sporulation present but less than $25 \%$ of a fully sporulating lesion, $3=$ sporulation present and equal to 26 to $50 \%$ of a fully sporulating lesion, $4=$ sporulation present and equal to 51 to $75 \%$ of a fully sporulating lesion, and $5=$ sporulation similar to a fully sporulating susceptible lesion. 
bers at 20 to $22^{\circ} \mathrm{C}$ overnight (15). Plants were removed from dew chambers and placed in trays $(5$ by 53 by $80 \mathrm{~cm}$ ) in the greenhouse at 20 to $25^{\circ} \mathrm{C}$ under a $16-\mathrm{h}$ photoperiod and watered from below by flooding to a depth of $3 \mathrm{~cm}$. Supplemental light was provided by 1,000-watt Metalarc lights (Sylvania, Danvers, MA) spaced 0.6 $\mathrm{m}$ apart and $1.2 \mathrm{~m}$ above the bench.

Disease severity was evaluated on the first trifoliate leaf; however, the unifoliate leaf was evaluated on a few plants where growth was slower. A disease severity scale of 1 to 5 was used. The scale was based on lesion density, where $1=$ no visible lesions, 2 = few scattered lesions present, 3 $=$ moderate number of lesions on at least part of the leaf, $4=$ abundant number of lesions on at least part of the leaf, and $5=$ prolific lesion development over most of the leaf (16). The presence of the tan- colored lesion type (TAN) or reddishbrown (RB) lesion type also was recorded. The TAN lesion type was considered a susceptible reaction, whereas the RB lesion type was considered resistant (1). Cultivars that had plants with both RB and TAN lesion types on either the same leaf or on different plants were identified as a mixed reaction. A rating of the sporulation within lesions also was evaluated on a 1to-5 scale, where $1=$ no sporulation, $2=$ sporulation present but less than $25 \%$ of a fully sporulating lesion, $3=$ sporulation present and equal to 26 to $50 \%$ of a fully sporulating lesion, $4=$ sporulation present and equal to 51 to 75 of a fully sporulating lesion, and $5=$ sporulation similar to a fully sporulating susceptible lesion. This visual assessment or "sporulation rating" was developed to evaluate materials more rapidly than counting individual uredinia within a lesion and quantifying the spores produced by those uredinia. This assessment combines uredinia number within a lesion and the production of urediniospores within uredinia and also has been used in the evaluation of soybean germplasm for resistance to soybean rust (M. R. Miles, unpublished data).

All statistical analysis was done using JMP statistical software (version 5.01; SAS Institute, Inc., Cary, NC). Data from the four inoculation periods were combined for analysis of variance. Cultivar and isolate means were separated using Student's least significant difference, $P=$ 0.05 , calculated with the appropriate error terms from the analysis of variance.

\section{RESULTS}

Soybean rust severity differed significantly by isolate and by cultivar. The most
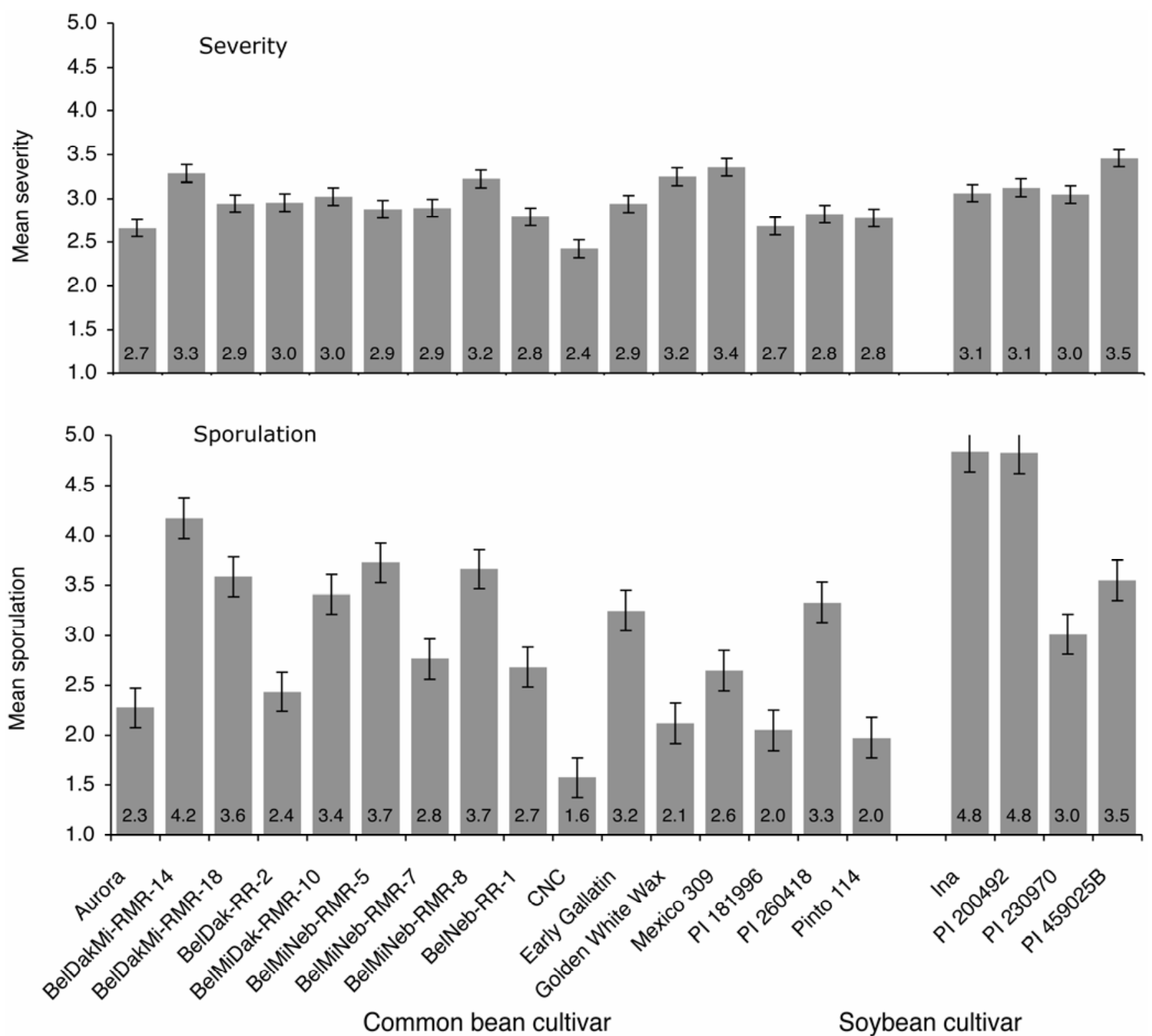

Fig. 1. Mean soybean rust severity and sporulation, with standard error of the cultivar mean (bars) from 16 common bean and four soybean cultivars when inoculated in seedling screens with six isolates of Phakopsora pachyrhizi at the United States Department of Agriculture-Agricultural Research Service Foreign Disease-Weed Science Research Unit Biosafety Level 3 Plant Pathogen Containment Facility in Ft. Detrick, MD. 
severe soybean rust was observed with the P. pachyrhizi isolates BZ01-1, PG01-2, and ZM01-1, which were significantly more severe than TH01-1, whereas TW72-1 and TW80-2 were intermediate (Table 2). The moderately susceptible soybean 'Ina' had a mean severity of 3.1 when averaged across all isolates (Fig. 1) and was similar to PI 200492 and PI 230970, the sources of the Rppl and Rpp2 genes, respectively. Three of the common bean cultivars, Aurora, CNC, and PI 181996, had lower severities than Ina. These three common bean cultivars were among those with the lowest mean severity when inoculated with each of six $P$. pachyrhizi isolates. The remaining common bean cultivars were intermediate, with means ranging from 2.8 to 3.4 , and were similar to the soybean cultivars. The soybean accession PI 459025B was the most susceptible, with a mean severity of 3.5. The cultivar-isolate interaction also was significant, indicating that all cultivars did not respond similarly to each isolate.

Since there was a significant cultivarisolate interaction for severity, the data were analyzed and presented by isolate. Mean soybean rust severities ranged from 2.1 to 4.0 for both common bean and soybean cultivars when evaluated against individual isolates (Fig. 2). The interaction was readily seen with Early Gallatin and PI 200492, which had lower mean severity with BZ01-1 compared with PG01-2 and TW72-1; PI 260418, which had lower mean severity with TH01-1 and TW80-2 compared with BZ01-1, PG01-2, and TW72-1; and PI 230970, which had lower mean severity with TW72-1 when compared with the other isolates. The interaction also was due to a lack of separation among cultivars with ZM01-1. When inoculated with ZM01-1, the only difference was between the cultivars with the lowest severity, PI 260418 and CNC, and the cultivars with the greatest severity, BelNeb-RR-1 and PI 459025B.

The differences in mean sporulation ratings between isolates and among cultivars also were statistically significant $(P=$ 0.05). Mean sporulation rating for the $P$. pachyrhizi isolates ranged from 2.7 for TW72-1 to 3.3 for TH01-1 and ZM01-1, whereas the isolates BZ01-1, PG01-2, and TW80-2 were intermediate, with mean sporulation ratings of 3.1 (Table 2). The mean sporulation rating of the common bean cultivars, when averaged across isolates, ranged from 1.6 for $\mathrm{CNC}$ to 4.2 for BelDakMi-RMR-14 (Fig. 1). The mean sporulation rating for the soybean cultivars ranged from 3.0 for PI 230970 to 4.8 for both Ina and PI 200492. As a group, the sporulation level on the soybean cultivars tended to be greater than that on the common bean cultivars. As with the severity assessment, there was a significant cultivar-isolate interaction observed with the sporulation rating. All cultivars did not respond the same to all isolates; therefore, the data were analyzed and presented by isolate (Fig. 3).

The cultivar-isolate interaction for sporulation was readily seen with several of the common bean cultivars (Fig. 3).
When compared with other isolates, reduced sporulation was observed in Aurora and BelMiNeb-RMR-8 when inoculated with TW72-1, BelDak-RR-2 and Early Gallatin when inoculated with BZ01-1 and TW72-1, BelNeb-RR-1 when inoculated
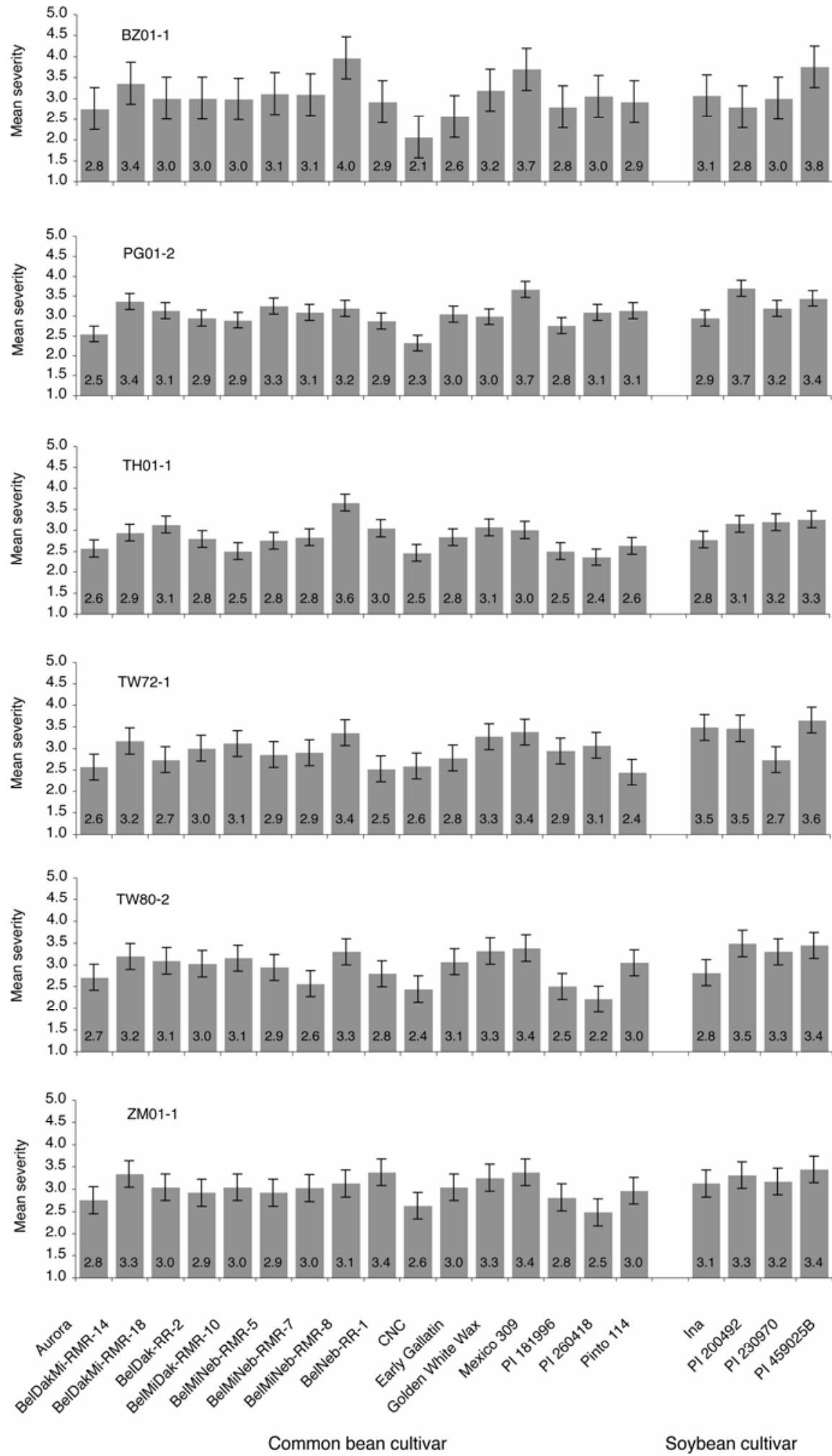

Fig. 2. Mean soybean rust severity rating with standard error of the cultivar mean (bars) from 16 common bean and four soybean cultivars evaluated against six Phakopsora pachyrhizi isolates in an experiment done four times at the United States Department of Agriculture-Agricultural Research Service Foreign Disease-Weed Science Research Unit Biosafety Level 3 Plant Pathogen Containment Facility in Ft. Detrick, MD. 
with PG01-2 and TW72-1, and BelMiNebRMR-7 when inoculated with TW72-1 and TW80-2. The soybean cvs. Ina, PI 200492, and PI 459025B also showed a differential response, with reduced sporulation when inoculated with TW72-1. CNC, PI 181996, and Pinto 114 had low sporulation with all isolates, whereas BelDakMi-RMR-14 and
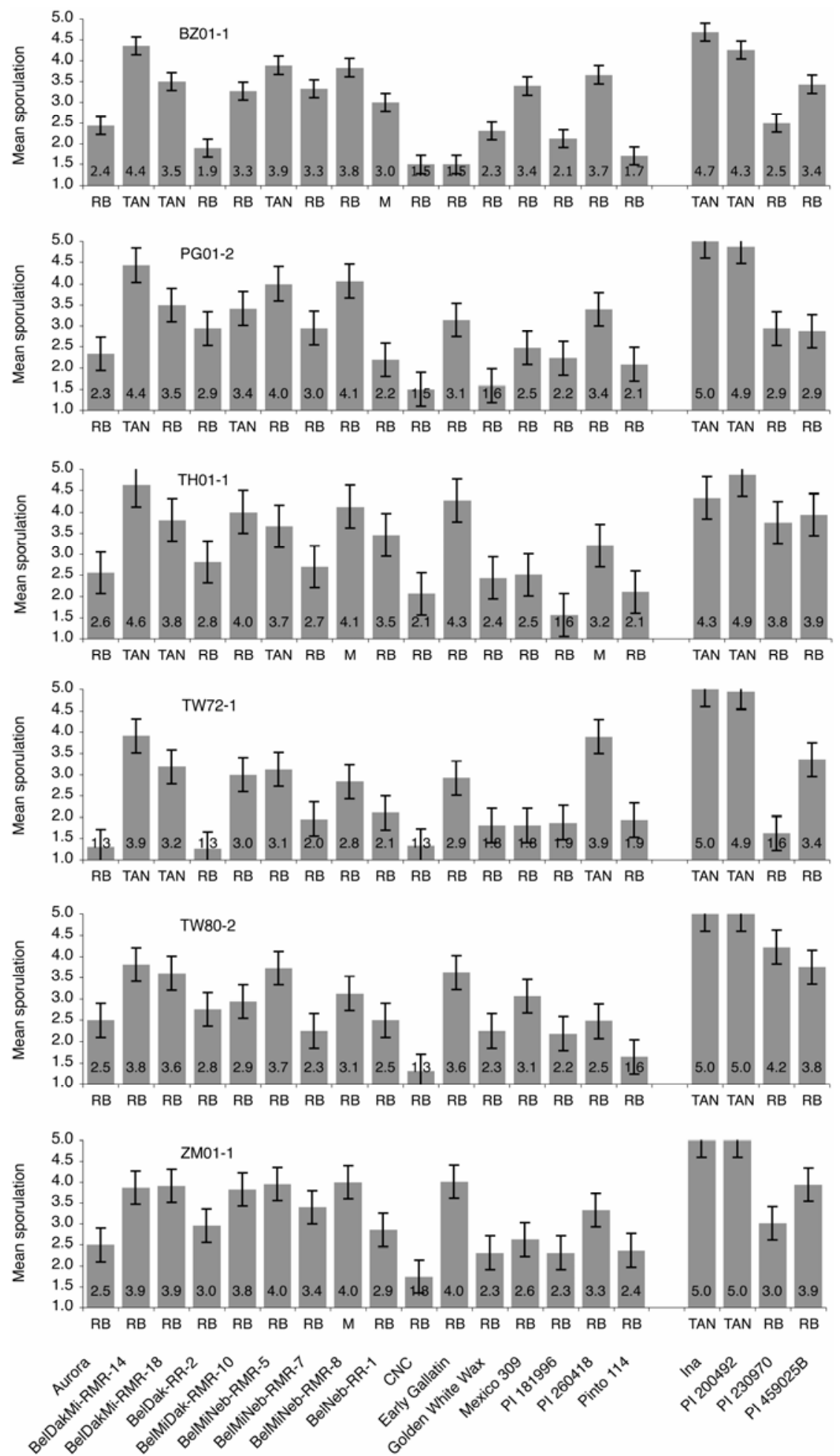

Common bean cultivar

Soybean cultivar

Fig. 3. Mean soybean rust sporulation rating with mean standard error of the cultivar mean (bars) and lesion type for each of the 16 common bean and four soybean cultivars evaluated against six Phakopsora pachyrhizi isolates in an experiment done four times at the United States Department of Agriculture-Agricultural Research Service Foreign Disease-Weed Science Research Unit Biosafety Level 3 Plant Pathogen Containment Facility in Ft. Detrick, MD. Lesion types: RB = red-brown resistant lesion type with a red-brown color, TAN = susceptible lesion type with a tan color, and $\mathrm{M}=$ mixture of both lesion types on same leaf.

BelMiNeb-RMR-5 had high sporulation with all isolates.

Lesion type, or the presence of the resistant RB or susceptible TAN reaction, also varied. Most of the common bean cultivars had the RB lesions when inoculated with all six isolates (Fig. 3). However, BelDakMi-RMR-14, BelDakMi-RMR-18, BelMiNeb-RMR-5, BelMiNeb-RMR-8, BelNeb-RR-1, and PI 260418 had TAN or mixed lesion types with one or more of the isolates. The mixed lesion type was the result of an inconsistent $\mathrm{RB}$ response, where RB lesions were observed on one or more of the four plants evaluated for within a cultivar but were not always found on plants of that cultivar when the experiment was repeated. It also should be noted that, within some of the common bean cultivars identified as RB, there were one or two individual plants where the presence of the RB lesion type was not observed. The lesion types within the soybean accessions were more consistent; RB lesions were observed for each isolate on both PI 230970 and PI 459025B at each inoculation date, while Ina and PI 200492 had TAN lesions with all six isolates.

Mean sporulation ratings within RB lesions ranged from 1.5 to 4.3 (Fig. 3). The common bean cvs. Aurora, CNC, PI 181996, and Pinto 114 had consistent RB lesions and low sporulation ratings ranging from 1.3 to 2.5 when inoculated with all six isolates. However, Early Gallatin, which also had consistent RB lesions, varied in sporulation ratings ranging from 1.5 to 4.3 for individual isolates. BelMiNeb-RMR-5 inoculated with PG01-2 and ZM01-1, as well as BelMiNeb-RMR-8 inoculated with PG01-2, and Early Gallatin inoculated with TH01-1 and ZM01-1, had RB lesions but sporulation ratings greater than 4.0. Among the soybean accessions, PI 230970 had RB lesions when inoculated with TW80-2, but a mean sporulation rating of 4.3. In all cases where a common bean differential had a TAN or mixed reaction when inoculated with an individual isolate, the mean sporulation rating was greater than 3.0. Within the common bean cultivars, low sporulation ratings were seen only with the RB lesion type. This same pattern was observed among soybean cultivars: low sporulation was associated with RB lesions while the TAN lesions had high sporulation. However, there were common bean and soybean cultivars with RB lesions that had sporulation ratings similar to cultivars with TAN lesions.

\section{DISCUSSION}

As a group, the common bean cultivars evaluated in this study appeared to have resistance to soybean rust, but none were immune. When compared with the moderately susceptible soybean cv. Ina, the common bean cultivars were similar in severity but had less sporulation, and most 
had the RB lesion type. Aurora, CNC, and Pinto 114 were the most resistant of the common bean cultivars to all six $P$. pachyrhizi isolates, with lower severity, less sporulation, and consistent RB lesions. $\mathrm{CNC}$ previously was reported to have resistance to TW72-1, producing RB lesions with no uredinia (27). In this study, when CNC was inoculated with TW72-1, the RB lesion type was seen, but with uredinia sporulating at low levels.

A differential response was observed statistically with a cultivar-isolate interaction among the common bean cultivars when inoculated with the six isolates of $P$. pachyrhizi for both severity and sporulation levels, as well as visually with the presence or absence of an RB lesion type. Among the common bean cultivars, the presence of the known $U r$ genes for resistance to $U$. appendiculatus, singly or in combination, did not correspond with the reaction of these cultivars to $P$. pachyrhizi or the differential responses identified with soybean rust severity, sporulation level, or presence of the RB lesion. CNC and Aurora were among the cultivars with the lowest mean severity and least sporulation, and produced consistent RB lesions with all six of the soybean rust isolates. Although the $U r$ genes in $\mathrm{CNC}$ are not known, Aurora has the $U r-3$ gene. This gene did not appear to be contributing to soybean rust resistance, because other common bean differentials known to have the $U r-3$ gene were not as resistant as Aurora. There was no apparent resistance pattern identified in Early Gallatin, Golden White Wax, Mexico 309, or PI 181996, which have the $U r-4, U r-6, U r-5$, and $U r-$ 11 genes, respectively. Further, there was no pattern that carried into the common bean cultivars with combinations of these genes. The common bean cultivars with four genes for resistance to U. appendiculatus, BelMiDak-RMR-18 and BelMiNebRMR-7, were among the most susceptible to all isolates of $P$. pachyrhizi. However, Pinto 114, not known to have a $U r$ gene and susceptible to most current isolates of $U$. appendiculatus, had low sporulation ratings and consistent $\mathrm{RB}$ lesion type and was among the most resistant common bean cultivars to all isolates of $P$. pachyrhizi. Thus, resistance to soybean rust in common bean must be derived independently from the $U r$ genes evaluated in this study.

Because the RB lesion type is a resistance response (1), one would expect lower sporulation ratings on cultivars with consistent RB lesions than on cultivars with mixed or the susceptible TAN lesions. Reduced sporulation was associated with $\mathrm{RB}$ lesions, but several of the common bean differentials with RB lesions also had high sporulation ratings. In all cases where a TAN or mixed reaction was reported, the sporulation ratings were high (greater than 3.0).
The use of the RB lesion type as a differential reaction was complicated by the presence of the mixed reaction. A mixed reaction often was due to differences in the expression of the $\mathrm{RB}$ reaction between experimental repeats of the individual $P$. pachyrhizi isolates. In addition, RB lesions were not consistently observed on cultivars when the experiment was repeated. Additionally, not all plants of a cultivar inoculated on the same date had RB lesions. The conditions that influence this variability are not known, but it may have been due to an environmental effect that interfered with normal disease development, or experimental error resulting from evaluations that varied from person to person. Further investigations into the causes of this variability are needed before the trait can be used consistently in a differential evaluation.

The range in mean severity among the cultivars when inoculated with individual $P$. pachyrhizi isolates was narrow, between 2.1 and 4.1. The range of the mean sporulation levels was 1.3 to 5.0 , encompassing the full range of the evaluation scale. Severity may have been influenced by inoculum concentration, inoculum viability, and differences between observed germination rates and infection rates. The limited range observed with the severity assessment and the potential effects of inoculum concentration and viability limit its usefulness in a differential evaluation. The wider range and more consistent results seen with sporulation level make it a better candidate for use in a differential evaluation.

The threat of soybean rust caused by $P$. pachyrhizi does not appear to be as severe in common bean production as it is with soybean production. The common bean cultivars evaluated in this study were all more resistant than the moderately susceptible soybean cv. Ina. There are no reports of a common bean production field infected with $P$. pachyrhizi in either southern Africa or South America, where the pathogen has had an impact on soybean production. The report from South Africa (5) was from a germplasm evaluation trial where only a few of the common bean cultivars were infected with soybean rust, though the soybean plants in the adjacent fields were heavily infected. This field observation along with our greenhouse results indicate that, as a whole, the common beans have more resistance than soybean to $P$. pachyrhizi.

\section{ACKNOWLEDGMENTS}

This research was supported by the United Soybean Board as Projects 2229, 3217 and 4217. We thank T. Herman and T. Lynch for organizing the sets of seed sent to the FDSWRU; and C. Austin, J. Garrett, S. Diepold, and C. Stone for their technical assistance with the seedling evaluations at the FDWSRU.

\section{LITERATURE CITED}

1. Bromfield, K. R. 1984. Soybean Rust, Monograph No. 11. American Phytopathological So- ciety, St. Paul, MN.

2. Bromfield, K. R., and Hartwig, E. E. 1980. Resistance to soybean rust Phakopsora pachyrhizi and mode of inheritance. Crop Sci. 20:254-255.

3. Bromfield, K. R., Melching, J. S., and Kingsolver, C. H. 1980. Virulence and aggressiveness of Phakopsora pachyrhizi isolates causing soybean rust. Phytopathology 70:17-21.

4. Burdon, J. J., and Marshall, D. R. 1981. Interand intra-specific diversity in the diseaseresponse of Glycine species to the leaf-rust fungus Phakopsora pachyrhizi. J. Ecol. 69:381-390.

5. DuPreez, E. D., van Rij, N. C., Lawrence, K. F., Miles, M. R., and Frederick, R. D. 2005. First report of soybean rust (Phakopsora pachyrhizi) on dry beans in South Africa. Plant Dis. 89:206.

6. Frederick, R. D., Snyder, C., Peterson, G. L., and Bonde, M. R. 2002. Polymerase chain reaction assays for the detection and discrimination of the soybean rust pathogens Phakopsora pachyrhizi and P. meibomiae. Phytopathology 92:217-227.

7. Hartman, G. L., Bonde, M. R., Miles, M. R., and Frederick, R. D. 2004. Variation of Phakopsora pachyrhizi isolates on soybean. Pages 440-446 in: Proc. VII World Soybean Res. Conf. F. Moscardi, ed. Emprapa Soybean, Londrina.

8. Hartman, G. L., Saadaoui, E. M., Tschanz, A. T., and Scientific Editors. 1992. Annotated Bibliography of Soybean Rust (Phakopsora pachyrhizi Sydow), AVRDC Library Bibliography Series 4-1. Asian Vegetable Research and Development Center, Tropical Vegetable Information Service. Taipei.

9. Hartwig, E. E. 1986. Identification of a fourth major gene conferring resistance to soybean rust. Crop Sci. 26:1135-1136.

10. Hartwig, E. E., and Bromfield, K. R. 1983. Relationships among three genes conferring specific resistance to rust in soybeans. Crop Sci. 23:237-239.

11. Kelly, J. D., Stavely, J. R., and Miklas, P. N. 1996. Proposed symbols for rust resistance genes. Annu. Rep. Bean Improv. Coop. 39:2531.

12. Lin, S. Y. 1966. Studies on the physiologic races of soybean rust fungus, Phakopsora pachyrhizi Syd. J. Taiwan Agric. Res. 15:24-28.

13. Lynch, T. N., Marois, J. J., Wright, D. L., Harmon, P. F., Harmon, C. L., Miles, M. R. and Hartman, G. L. First report of soybean rust caused by Phakopsora pachyrhizi on Phaseolus species in the United States. Plant Dis. 90:970.

14. McLean, R., and Byth, D. E. 1980. Inheritance of resistance to rust (Phakopsora pachyrhizi) in soybean. Aust. J. Agric. Res. 31:951-956.

15. Melching, J. S., Dowler, W. M., Koogle, D. L., and Royer, M. H. 1983. Effects of duration, frequency, and temperature of leaf wetness periods on soybean rust. Plant Dis. 73:117-122.

16. Miles, M. R., Frederick, R. D., and Hartman, G. L. 2006. Evaluation of soybean germplasm for resistance to Phakopsora pachyrhizi. Plant Health Progress: doi:10.1094. PHP-2006= 0104-01-RS.

17. Misman, R., and Purwati, E. S. 1985. A study on host plant types of soybean rust fungi (Phakopsora pachyrhizi Syd.) on various types of legumes. Bull. Ilmaih Unsoed 11:68-82.

18. Ono, Y., Buritica, P., and Hennen, J. F. 1992. Delimitation of Phakopsora, Physopella and Cerotelium and their species on Leguminosae. Mycol. Res. 96:825-850.

19. Pastor-Corrales, M. A., Stavely, J. R., Kelly, J. D., Grafton, K. F., Steadman, J. R., Coyne, D. P., Lindgren, D. T., and Scully, B. T. 2001 Rust and mosaic resistant bean germplasm releases. 1997-1999. Annu. Rep. Bean Improv. Coop. 44:101-102. 
20. Pastor-Corrales, M. A., Stavely, J. R., Kelly, J. D., Steadman, J. R., Coyne, D. P., and Lindgren, D. T. 2005. Release of BELMINEBRMR-8, -9, -10, -11, -12, and -13 , erect, short vine, rust and mosaic resistant great northern bean germplasm lines. Annu. Rep. Bean Improv. Coop. 48:194-196.

21. Poonpolgul, S., and Surin, P. 1985. Physiological races of soybean rust in Thailand. Thai Phytopathol. 5:119-120.

22. Rytter, J. L., Dowler, W. M., and Bromfield, K. R. 1984. Additional alternative hosts of Phakopsora pachyrhizi, causal agent of soybean rust. Plant Dis. 68:818-819.

23. Schneider, R. W., Hollier, C. A., Whitam, H.
K., Palm, M. E., McKemy, J. M., Hernández, J. R., Levy, L., and DeVries-Paterson, R. 2005. First report of soybean rust caused by Phakopsora pachyrhizi in the continental United States. Plant Dis. 89:774.

24. Sconyers, L. E., Kemerait, R. C., Brock, J., Phillips, D. V., Jost, P. H., Sikora, E. J., Gutierrez-Estrada, A., Mueller, J. D., Marois, J. J., Wright, D. L., and Harmon, C. L. 2006. Asian soybean rust development in 2005: A perspective from the southeastern United States. APSnet 2006.

25. Shin, D. C., and Tschanz, A. T. 1986. Studies on physiological reactions of soybean cultivars tolerant and susceptible to rust (Phakopsora pachyrhizi Syd.). Korean J. Crop Sci. 31:440 446.

26. Stavely, J. R., and Pastor-Corrales, M. A. 1989. Rust. Pages 159-164 in: Bean Production Problems in the Tropics. H. F. Schwartz and M. A. Pastor-Corrales, eds. CIAT, Cali, Colombia.

27. Stavely, J. R., Rytter, J. L., and Royer, M. H. 1985. Virulence of the soybean rust pathogen Phakopsora pachyrhizi on Phaseolus vulgaris cultivars. Annu. Rep. Bean Improv. Coop. 28:35-36.

28. Vakili, N. G. 1979. Field survey of endemic leguminous hosts of Phakopsora pachyrhizi in Puerto Rico. Plant Dis. Rep. 63:931-935. 